\title{
Why consumers do not provide online reviews?
}

\author{
Daniele Doneddu ${ }^{1,2}$, Irina Novoshilova ${ }^{3}$ \\ ${ }^{1}$ School of Management, Swansea University, Swansea SA1 8EN, UK \\ ${ }^{2}$ SCIENTIA group, Swansea, UK \\ d.doneddu@swansea.ac.uk \\ ${ }^{3}$ Faculty of Management, Law and Social Sciences, University of Bradford, Bradford, UK \\ i.novozhilova@bradford.ac.uk
}

\begin{abstract}
In light of the very high popularity of electronic word of mouth in the form of products and services reviews on the internet and its critical importance for businesses, the aim of this research is to investigate why customers who buy skincare products do not engage in eWOM by not leaving reviews about these products online. This research adopts a qualitative nature, using semi-structured in-depth interviews. Respondents' group consists of the same amount of males and females who were asked questions regarding their electronic and traditional word of mouth experiences. Received responses demonstrate that laziness, lack of general interest in skin care and lack of feeling altruistic towards consumers online are the key factors preventing consumers from leaving reviews about skin care online.
\end{abstract}

Keywords: Online reviews, eWOM, skincare

\section{Introduction}

Word of mouth communications help spreading information about products and services, boosting prospects' awareness [1, 2]. Firms attempt to trigger word of mouth activities and regulate its matters as much as they can [3].

Internet resources such as chat rooms, opinion sharing portals, social networking websites, email etc. have allowed word of mouth to expand into online space as consumers started sharing their experiences about products and services on the internet. This led to the creation of various internet communities. This process is referred to as electronic word of mouth (also known as word of mouse). Electronic word of mouth (eWOM) is "any positive or negative statement made by potential, actual, or former customers about a product or company, which is made available to a multitude of people and institutions via the Internet” [3].

A number of studies investigated why consumers engage in eWOM communications (see, amongst others, $[3,4]$ ). However, limited number of studies investigated why consumers do not provide eWOM. Thus, the aim of this research is to explore the reasons why consumers do not provide eWOM. The findings will advance under- 
standing of information dissemination online and allow companies to enhance their strategies to provide eWOM regarding their product/service.

\section{$2 \quad$ Literature review}

\subsection{Motivations to provide eWOM}

Based on the literature, the following five most common motivations to engage in eWOM have been identified [5]:

Altruism: a concept by which activity connected with disinterested concern for the well-being of others is understood. It correlates with the concept of selflessness - that is, with the sacrifice of their benefits in favour of the benefit of another person, other people, or in general - for the common good [6]. Thus, altruism can be described as a motivation with an aim to raise the welfare of one or more persons other than of oneself [7]. According to [8], altruism significantly influences brand communities on social media websites.

Self-enhancement: an individual's motivation to demonstrate one or more selfdomains positively in order for other people to accept and favour them. It also helps to sustain self-esteem [9]. Humans usually lean towards self-enhancing, making it their vital motivation [10]. A study by Hennig-Thurau et al. [3] tested eleven motives to provide eWOM using a sample of 2083 German individuals who use various opinion-sharing platforms. Results indicated that self-enhancement is one of the most important motives for users to share their opinion on online platforms.

Venting feelings: believed to be beneficial for an individual. When emotions are expressed, it helps a person to go back to a more serene condition [11]. Based of research studies [12, 13], it is apparent that when a client is dissatisfied, they are unlikely to complain to a firm. Instead, they prefer to release their negative feelings through communicating their opinion to others. Lee and Hu [14] noted that frustrated clients are likely to make public complaint online.

Social benefits. When consumers engage in online communication, they become part of the web-based group. Users may perceive this form of connection as a social benefit, as it allows them to get integrated into a new social network's structure. Therefore, it can be argued that users communicate through eWOM in order to be part of online groups. Consumers may leave messages on fora, reviews websites and other user generated resources to gain social benefits [3, 15]. Choi and Scott [16] found female social networks users were motivated to communicate on these platforms because they felt part of a community and because it supported their identification.

Economic incentives. Some consumers engage in eWOM in order to receive economic incentives, such as discounts and electronic points vouchers granted after posting a review on the opinion platform or brand website [17]. Wirtz and Chew [18] conducted an experiment using 215 individuals. Results illustrated that those who received a financial incentive are more motivated to generate eWOM. 


\subsection{Information sharing}

There is a significant amount of studies researching why people engage in offline and online word of mouth. When it comes to the question why individuals refuse to post reviews online, it can be helpful to look at the broader picture. Posts, messages, other forms of expressing opinions are all essentially processes of information sharing.

In an internet context, information sharing is the core activity. Internet substantially consist of the data created and shared by the users. This means that all the individuals writing blog posts, interacting in online communities, chatting etc. are content creator or sharers. This category of users is defined as posters. Nevertheless, there is another type of online behavior, opposite to posters, referred to as lurking [19]. In fact, lurkers represent the largest part of the internet: $>90$ percent of the online users [20-22]. Lurking is not clearly defined by researches but it is normally connected to avoidance of posting and nonparticipation behaviour. Lurkers are described as passive or inactive, silent and those who do search for information and read online content but do not contribute themselves [19, 23].

When discussing reasons for lurkers to lurk, it is important to mention that lurking behaviour is triggered primarily by individuals' greater demand for information [24, 25]. Lurkers therefore do not write anything on online platforms because their demand for information is fulfilled without posting anything [22]. According to [26], lurking is a consequence of excessive amount of information users receive online. This overload may result in a person trying to avoid engaging into this turmoil.

In their study, Nonnecke and Preece [27] identified reasons for lurkers to lurk. They conducted semi-structured in-depth interviews with ten participants who were identified as online group members who behaved like lurkers. Interviewees named 79 reasons for not posting online and the researchers concluded that lurking cannot be solely defined as an absence of posting. Most voiced reasons for lurking included:

1) Anonymity, privacy and safety. Users often want to remain anonymous when using the internet and are concerned about their personal data safety in case of sharing information in online spaces. People online can essentially choose who they want to be as they are unknown to others. Therefore, some users stress the issue of trust [28]. Bishop [29] also claims lurkers avoid posting due to the fear of losing privacy.

2) Time and work related constraints. A situation when individuals claim not to have enough time to post or when they could not use their email as it was a work email.

3) Message volume and quality. Interview participants mentioned that too low or too high amount of messages in the community prevent them from posting. Also, unsatisfactory quality of the information provided (such as off-topic conversations) turn user away from participating.

4) Shyness over public posting. Despite the internet being largely anonymous and users not seen by each other, some individuals are still cautious and hesitant about posting. This was also supported by Katz [20]. 


\section{Research method}

The study was conducted in the context of skincare product. As the aim of this research is to explore factors affecting providing eWOM, semi-structured interviews were chosen. 8 participants ( 4 males and 4 females), using convenience sampling, participated in this study. The full discussion guide can be provided upon request. In order to analyse interviews, NVivo software was used.

\section{$4 \quad$ Research findings}

Here below we report some of the research findings in relation to our study.

\subsection{Factors preventing the posting of a review}

In terms of factors preventing consumers from sharing their opinions online, interviewees' responses could be divided into two categories: i) customer characteristicsspecific and ii) circumstance-specific reasons preventing from eWOM communication. Similar to Mangold, Miller and Brockway [30] and Wolny and Mueller [31], the researchers divided motives to engage in WOM into dependent on customer personal characteristics and context in which customer is situated.

i) Customer characteristics-specific. 50 percent of the respondents reported that being lazy was their main reason for not leaving skin care reviews online. 25 percent also mentioned that they "could not be bothered" and did not care about leaving reviews after using a product. Some respondents specified that sharing their opinion online: "doesn't come to my mind" and "I never actually thought about leaving a review after buying anything".

Almost all interviewees expressed no interest in skin care products in general, as a topic. After saying that, they specified that this was actually the reason for not providing the internet with their skin care products opinion.

“....if there's anything I'm interested in, then I might leave my opinion as well. If I am very interested, for example a discussion about football, I leave some comments on football groups once or twice a week. So I don't leave reviews about skin care product because I am not interested in them.”

Two respondents indicated that they do not leave reviews as they feel that their opinion wouldn't really matter due to high amount of other reviews online, consequently they do not see any reason to add on to other comments and repeating them.

"Cos there's so much out there that really my opinion wouldn't really matter because there's so much other people's opinions I would probably be saying the same thing as two hundred other women so I don't see any point of repeating other reviewers."

They also mentioned that they did not feel their opinion was needed and expressed the idea that companies would not even pay attention to their reviews.

"I am not sure anyone would benefit from my opinion. If I was sure my opinion was needed or someone would use it, I would share, but otherwise, no" 
One person repeatedly mentioned that they avoided leaving reviews due to considering it a waste of time. It is important to note that the two respondents expressing opinions about repeating the same concepts as other people and not feeling their opinion was important for anyone are themselves active skin care lurkers but they never leave any reviews about this or other product categories online.

"...Because for me it takes extra time and I feel that I would rather do something else in that extra time”

All above mentioned hindering factors were identified by the researchers as customer characteristics-specific because they come from the individuals' views and feelings, which were formed prior to the situation where they were expected to engage in electronic word of mouth. These are based on consumers' existing beliefs, interests and habits.

ii) Circumstance-specific. Context specific factors affect individual's intentions to engage in electronic word of mouth. An example of this is a situation when a respondent mentioned not leaving a review when a firm's website or opinion platform is difficult to navigate or has irritating pop-ups. This can be marked as technological problems.

Cyber bullying was also named as one circumstantial factor that stops a person from sharing their opinion. However, only 3 persons demonstrated that they were influenced by other users online.

As mentioned above, three individuals shared their concern about posting their reviews online because they are not confident about sharing an opinion which is opposite to what is already published.

"If I consider leaving a review, I am worried that if it is negative, I might be the wrong one. I mean, what If I got a faulty, defective product which was just one in a batch, but generally it is good for the majority of people? Then I would feel wrong. I would feel like I would make a bad impact for the company. I would not like to mislead people with my negative emotions. So If I see that mostly people post positive reviews and I have a negative, I would probably doublethink.”

"...So if my opinion fits others, I would go with the flow and if its contrary to others, then I would avoid posting it.”

“...if you have bad experience about a product and everyone else's reviews say it's amazing, then as a person, it might stop you from saying something bad because you might think like - maybe I've made a mistake or I use that product wrongly. It could stop me and maybe make me think."

Furthermore, 75 percent of posting respondents stated that they would never leave a review if they have a neutral opinion about the product.

\subsection{Other findings:}

Level of satisfaction. During the interviews it became apparent, that the level of satisfaction with a product or service determines participants' intentions to share their opinions online. 37.5 percent of respondents stated that they would only post reviews 
if they were extremely satisfied with the product and if it gave them outstanding results (specifically beauty products).

"If I have outstanding results, then I would post. But if it's negative or very negative I would not bother leaving my review."

"I think a very good experience would make me leave a review. If I want to leave a review, it's most likely going to be positive. So if I'm very happy with the product I'm more likely to leave a review."

Another 37.5 percent of interviewees reported they would only bother to leave their opinion if they had either a very negative or a very positive results.

"If the product is really excellent and it has affected me greatly I would definitely leave a positive review. And the same with a negative review - if I am extremely dissatisfied and the product was basically a disaster, then I will definitely post a negative review. So it's high ends of both sides, either very positive or extremely negative."

However, none of the participants demonstrated intentions to share neutral or just negative opinions on the internet.

"If I have nothing to say or if it is an everyday product and I feel no positive or negative emotions about it and I'm neutral, I would not really share that kind of opinion."

What would motivate consumer to leave online reviews. Respondents were asked about what they thought could motivate them to leave reviews and what they thought companies could do to trigger electronic word of mouth behaviour in them. One respondent mentioned that if he as a customer was given more attention from the company, he would be motivated to leave reviews.

"Sometimes probably just acknowledgement, recognition. Customers want to be heard, customers want to be noticed. So if there is a recognition, everyone would like to post reviews. Customers would like to see the reviews appreciated and maybe even shared. For example, ok here's a review of our customer John and here is what he thinks of our products. We're doing it, we are on it or something like that would be a good response of a company."

50 percent of interviewees mentioned that if they saw a message from a company asking them to leave their opinion online, if they realised their reviews mattered, they would be more likely to engage in eWOM.

"...I think that companies should let people know that their views count, because I think most people think that companies don't really care about their reviews. The company should ask in the advertising or maybe tell sales people when their products are sold, they should tell the customers to leave reviews because reviews matter."

"I think it's best if they can write on the package that they want people to leave reviews and that it's very important for them."

"Maybe if companies add the message to the advertising strategy that it is very important for them to get reviews so it's the kind of encourage customers to post reviews online"

Two respondents said that if they knew someone really needed their opinion and if they were asked to leave a review, they would definitely agree. 
"...if someone asks me to do that if someone really wants me to do that I will be happy to do that."

"If I was sure my opinion was needed or someone would use it, I would share."

Economic incentives have been mentioned by seven out of eight participants as a motivating factor to leave a product review. In addition to that, one individual stressed that having received any form of incentive, they would take time writing a good quality, descriptive review.

"Something - incentives, samples. Does not have to be anything big, but something, gratification. In this case, I would leave a very detailed, good quality review with good explanation of my opinion.”

"...getting some kind of incentive for example like on TripAdvisor, if you leave certain amount of reviews you get special status which brings you perks."

"I think giveaways would be a good idea, so if you buy something, leave a review and you would automatically enter a giveaway this would be stimulating to leave reviews."

They also mentioned that knowing that leaving review would result in company donating some money to charity would definitely make them leave reviews.

"They could also do something connected to charity. If, for example, they said that If I leave a review, they would donate some money to help animals or something like that, I would definitely participate.”

\section{Discussion}

Preece et al. [22] claim that at least 90 percent of internet users are lurkers. However, interestingly, in our (albeit involving a limited sample) study the percentage of posters was quite high among the respondents, which is contrary to above mentioned study results. In addition to that, when it comes to skin care, despite every participant using it and almost everyone reading reviews about this type of product, they never post their opinions online. Surely, the type of product must be taken into consideration, as noted by Gunn [32] in her research on what factors hinder electronic word of mouth in tourism industry. Therefore, it can be concluded that electronic word of mouth behaviour is influenced by and depends on the category of the product. This, in turn, implies that consumers' interests play their role in determining whether they would lurk or post about certain things. This will be discussed more in another part of this chapter.

In Nonnecke and Preece's study of reasons for lurking one of the most mentioned reason for not posting included anonymity and privacy [27]. This is very well supported by the research findings, demonstrating that respondents do not provide their personal information. It is important to mention that interviewees emphasised safety concerns as the most serious factor. In this way, these concerns tie in with Nonnecke and Preece's (2003) case study which reported users' perturb about safety [33]. Gunn's research also demonstrated concerns about confidentiality and security as preventing factors for leaving reviews online [32]. 
Preece, Nonnecke and Andrews [22], after examining 219 lurkers, spotted reasons such as "other community members gave the same answer I would", "I don't feel I would able to contribute anything" and "have no necessity to post". This research expands this finding by contributing additional factors hindering electronic word of mouth communication. These are coming from personal characteristics of respondents, causing them not to think about leaving reviews online after buying anything, indicating that something stops that thought from coming to their mind.

Preece, Nonnecke and Andrews [22] concluded that lurking behaviour was mainly caused by interaction with online community as only 13.2 percent of surveyed people reported their intention to lurk from the beginning. However, participants of this research demonstrated that the majority of lurkers had no intention to post reviews about any products from the start. And although some respondents said their potential reviews could be influenced by people who had already posted their opinion, they indicated that deliberate avoidance of publishing a review or absence of initial intention to publish was present from the start.

In addition to that, interview participants were asked whether they thought other users online had any influence on them. Although the majority of respondents claimed to not be affected by already published reviews, several participants expressed their worry of other internet users' opinions. One participant mentioned that they would not like to post a review which is opposite to existing ones and two interviewees demonstrated doubt of posting a negative review as they were not sure the unsatisfying performance of product was caused by themselves. Such reasoning may be the result of uncertainty and lack of confidence in participants. This finding shows similarity to Gunn's [32] research which identified lack of confidence as one of the main obstacles preventing from posting reviews. Her research also marked technological problems as barriers to electronic word of mouth. Contrary to these results, only one person described technological problems as preventing from leaving reviews.

Altruism was found by many researchers to be among the most significant reasons for individuals to engage in both traditional and electronic word of mouth [3, 34, 35]. As mentioned in the previous chapter, desire to help others was a very strong motive for all the participants to engage in traditional word of mouth communication. However, such behaviour was only expressed by 25 percent of participants who indicated the same reason for sharing their product reviews online in our preliminary study. These results could be considered as slightly contradicting the existing research outcomes, as previously conducted studies demonstrated that unselfish concern about other users is motivating people to engage in eWOM, the current study only found this reason valid for traditional word of mouth.

According to Wirtz and Chew's [18] experiment, a degree of product or service satisfaction does not necessarily lead to word of mouth being produced. However, a later study by Velázquez, Blasco and Gil Saura [36] found out that higher customer satisfaction results in a higher chance of intention to engage in electronic WOM and particularly positive electronic word of mouth behaviour. This result supports the outcomes of this research as a large proportion of respondents mentioned that being extremely satisfied with the product or results it provided is highly likely to motivate them for leaving a review. The same proportion of interviewed individuals said that 
they would only leave a review if they are either very happy or very unhappy. This so-called U-shaped connection between clients' happiness with the product and their willingness to spread word of mouth was explained by Anderson [37] and Herr, Kardes and Kim [38] as either extremely satisfied or very dissatisfied customers have higher intentions to engage in word of mouth. Interesting outcome was that none of the respondents demonstrated intention to share just neutral or only negative experiences on review websites. This finding is once again supporting the previous works such as Anderson's [37], Velázquez, Blasco and Gil Saura's [36] and Herr, Kardes and Kim's [38]. Therefore, finding regarding satisfaction levels are correlating with the existing research.

These findings also support researches which identified venting feelings as a motivation to engage in both traditional and electronic word of mouth. Wetzer, Zeelenberg and Pieters' [39] found out that urge to release highly negative emotions such as anger played as a strong motivation to share negative word of mouth. Sundaram, Mitra and Webster [34] emphasised very positive experiences as a factor motivating to sharing reviews as well. However, some works have been found to be contrary to conducted research. According to Tong, Wang, Tan and Teo [40], consumers engage in WOM to take a revenge on a company which left them dissatisfied. This was not supported by research for this study as not many participants showed interest to companies and even those who did, showed only positive intentions.

Product involvement demonstrated to be high for all participants as they mentioned always asking people around them and checking online opinions prior to buying skin care. However, it is contrary to research results of Wolny and Mueller [31] indicating that higher product involvement leads to higher motivation to engage in electronic word of mouth. Although interviewees emphasise the importance of skin care for them, they do not express general interest in these types of products. Due to general lack of interest in the topic, electronic word of mouth communication is not triggered in case of our interviewed respondents.

A very important and new finding of this research is the factor of laziness. It was discovered in this research and has not been found in the previous literature on the topic. A large proportion (50 percent) of respondents named laziness as a reason stopping them from posting their opinion online.

Also, the researcher recruited an equal amount of males and females for the research in order to test whether sex influenced electronic word of mouth participation in the skin care category. This was done as other researchers recruited higher amount of females for data collection. Our results show that there is no difference between males and females regarding the interest, involvement or level of willingness to potentially participate in eWOM. Only one male demonstrated no lurking behaviour in the context of skin care.

\section{Practical and theoretical implications}

This research advances the understanding of information dissemination online by identifying reasons for consumers not to engage in eWOM communications. Knowing 
the reasons of consumers to avoid leaving reviews can help managers to create a strategy for engaging customers to give feedback about skin care on the internet. Based on the data analysis, the following recommendations will be made. Due to research result showing that altruism is mostly motivating consumers to communicate through traditional word of mouth, it is recommended for companies to create marketing campaigns targeting feelings of consumers, which could motivate them to help people they do not know - other consumers online. To that effect, it would be useful to show the importance of online reviews for a company, which could also trigger altruism towards a business in those customers who are naturally predisposed to it.

Another recommendation is to raise the general interest about skin care. Only something which interests customers will make them spend time creating and posting a review. This could be done by publishing more educational material on skin care and skin care products topic.

Business' website should have their own review section. The process of posting a review must be made simple, fast and safe. It must also look trustworthy, should not ask for telephone number or any sensitive data. It is important to demonstrate that the website complies with all data protection laws, presenting themselves a responsible and reliable business.

In order to motivate consumer to leave a review, it is crucial to show them that a company truly cares for them and their opinion. Interacting with reviewers, highlighting their opinions, sharing them with wider audience may inspire lurkers to participate and feel like a part of a community.

Finally, almost all participants mentioned that receiving economic incentives such as discounts, vouchers, coupons etc. can be a strong motivating factor to provide reviews.

\section{Conclusion}

The aim of this research was to investigate why customers who buy skincare products do not engage in eWOM by not leaving reviews about products online. After conducting semi-structured in-depth interviews and analysing collected data, several factors hindering sharing reviews about skin care were found. Finding of the research indicate that firstly, individuals avoid leaving skin care reviews due to lack of interest or general excitement about the topic. They also reported being lazy to leave reviews and showed lower amount of altruism towards online users, compared to people they know in real life. Half of the respondents appeared to be posting about other categories of products rather than skin care, meaning that measure could be taken to attract them to publish reviews about skin care products too.

\section{References}

1. Yin, D., Mitra, S., Zhang, H.: Research note-when do consumers value positive vs. negative reviews? An empirical investigation of confirmation bias in online word of mouth. Information Systems Research 27, 131-144 (2016) 
2. Mikalef, P., Pappas, I.O., Giannakos, M.N.: Value co-creation and purchase intention in social commerce: the enabling role of word-of-mouth and trust. (2017)

3. Hennig-Thurau, T., Gwinner, K.P., Walsh, G., Gremler, D.D.: Electronic word-of-mouth via consumer-opinion platforms: what motivates consumers to articulate themselves on the internet? Journal of interactive marketing 18, 38-52 (2004)

4. Mikalef, P., Giannakos, M.N., Pappas, I.O.: Designing social commerce platforms based on consumers' intentions. Behaviour \& Information Technology 36, 1308-1327 (2017)

5. Ismagilova, E., Dwivedi, Y.K., Slade, E., Williams, M.D.: Electronic word of mouth (eWOM) in the marketing context: A state of the art analysis and future directions. Springer (2017)

6. Shechter, M., Freeman, S.: Nonuse value: reflections on the definition and measurement. Valuing the Environment: Methodological and Measurement Issues, pp. 171-194. Springer (1994)

7. Batson, C.D.: Why act for the public good? Four answers. Personality and Social Psychology Bulletin 20, 603-610 (1994)

8. Lee, D., Kim, H.S., Kim, J.K.: The impact of online brand community type on consumer's community engagement behaviors: Consumer-created vs. marketer-created online brand community in online social-networking web sites. Cyberpsychology, Behavior, and Social Networking 14, 59-63 (2011)

9. Alicke, M.D., Sedikides, C.: Self-enhancement and self-protection: What they are and what they do. European Review of Social Psychology 20, 1-48 (2009)

10.Fiske, S.T.: Social and societal pragmatism: commentary on augustinos, Gaskell, and Lorenzi-Cioldi. Representations of the social: bridging research traditions 249-253 (2001)

11.Parlamis, J.D.: Venting as emotion regulation: The influence of venting responses and respondent identity on anger and emotional tone. International Journal of Conflict Management 23, 77-96 (2012)

12.Best, A., Andreasen, A.R.: Consumer response to unsatisfactory purchases: A survey of perceiving defects, voicing complaints, and obtaining redress. Law \& Soc'y Rev. 11, 701 (1976)

13.Tschohl, J.: Do yourself a favor: Gripe about bad service. American Salesman 39, 3-5 (1994)

14.Lee, C.C., Hu, C.: Analyzing Hotel customers' E-complaints from an internet complaint forum. Journal of Travel \& Tourism Marketing 17, 167-181 (2005)

15.Oliver, R.L.: Whence consumer loyalty? Journal of marketing 63, 33-44 (1999)

16.Choi, J.H., Scott, J.E.: Electronic word of mouth and knowledge sharing on social network sites: a social capital perspective. Journal of theoretical and applied electronic commerce research 8, 69-82 (2013)

17.Dalkir, K.: Knowledge management in theory and practice. Routledge (2013)

18.Wirtz, J., Chew, P.: The effects of incentives, deal proneness, satisfaction and tie strength on word-of-mouth behaviour. International journal of service industry management 13, 141-162 (2002)

19.Edelmann, N.: Reviewing the definitions of "lurkers" and some implications for online research. Cyberpsychology, Behavior, and Social Networking 16, 645-649 (2013)

20.Katz, J.: Luring the lurkers. Slashdot. (1998) 
21.Nielsen, J.: Participation inequality: Encouraging more users to contribute. http://www. useit. com/alertbox/participation_inequality. html (2006)

22.Preece, J., Nonnecke, B., Andrews, D.: The top five reasons for lurking: improving community experiences for everyone. Computers in human behavior 20, 201-223 (2004)

23.Nonnecke, B., Andrews, D., Preece, J.: Non-public and public online community participation: Needs, attitudes and behavior. Electronic Commerce Research 6, 7-20 (2006)

24.Bartikowski, B., Walsh, G.: Attitude contagion in consumer opinion platforms: posters and lurkers. Electronic Markets 24, 207-217 (2014)

25.Wiertz, C., CHARLA, M., RUYTER, K.: Social capital production in a virtual p3 community. Journal of Consumer Research 34, 832-849 (2008)

26.Haythornthwaite, C.A.: Online knowledge crowds and communities. (2009)

27.Nonnecke, B., Preece, J.: Why lurkers lurk. AMCIS 2001 proceedings 294 (2001)

28.Blanchard, A.L., Markus, M.L.: The experienced sense of a virtual community: Characteristics and processes. ACM SIGMIS Database: the DATABASE for Advances in Information Systems 35, 64-79 (2004)

29.Bishop, J.: Transforming lurkers into posters: The role of the participation continuum. In: Proceedings of the Fourth International Conference on Internet Technologies and Applications (ITA11), pp. 1-11. (Year)

30.Glynn Mangold, W., Miller, F., Brockway, G.R.: Word-of-mouth communication in the service marketplace. Journal of services Marketing 13, 73-89 (1999)

31.Wolny, J., Mueller, C.: Analysis of fashion consumers' motives to engage in electronic word-of-mouth communication through social media platforms. Journal of marketing management 29, 562-583 (2013)

32.Gunn, R.: Silent Travlers: Barriers to Providing eWOM. (2017)

33.Nonnecke, B., Preece, J.: Silent Participants: Getting to Know Lurkers Better. In: Lueg, C., Fisher, D. (eds.) From Usenet to CoWebs: Interacting with Social Information Spaces, pp. 110132. Springer London, London (2003)

34.Sundaram, D.S., Mitra, K., Webster, C.: Word-of-mouth communications: A motivational analysis. ACR North American Advances (1998)

35.Yoo, K.-H., Gretzel, U.: Influence of personality on travel-related consumer-generated media creation. Computers in Human Behavior 27, 609-621 (2011)

36.Velázquez, B.M., Blasco, M.F., Gil Saura, I.: ICT adoption in hotels and electronic word-ofmouth. Academia Revista Latinoamericana de Administración 28, 227-250 (2015)

37.Anderson, E.W.: Customer satisfaction and word of mouth. Journal of service research 1, 517 (1998)

38.Herr, P.M., Kardes, F.R., Kim, J.: Effects of word-of-mouth and product-attribute information on persuasion: An accessibility-diagnosticity perspective. Journal of consumer research 17, 454-462 (1991)

39.Wetzer, I.M., Zeelenberg, M., Pieters, R.: “Never eat in that restaurant, I did!”: Exploring why people engage in negative word-of-mouth communication. Psychology \& Marketing 24, 661-680 (2007)

40.Tong, Y., Wang, X., Tan, C.-H., Teo, H.-H.: An empirical study of information contribution to online feedback systems: A motivation perspective. Information \& Management 50, 562-570 (2013) 